\title{
RESULTS OF ANALYSIS OF Ti FOIL AFTER GLOW DISCHARGE WITH DEUTERIUM
}

\author{
I. B. Savvatimova, D. V. Gavritenkov \\ FSUI SRI SFA «Lutch»
}

\begin{abstract}
In this study we report on the surface structure, distribution and isotopic composition of elements found on Ti cathodes before and after glow discharge in plasma, during which excess heat was produced. Irradiation was carried out with deuterium ions with a discharge voltage below 1000 volts, with a current of 10 to $20 \mathrm{~mA}$.

The analysis of the surface structure and of elemental composition of the Ti sample was carried out with a scanning electron microscope with Energy Dispersive X-ray Spectroscopy (EDS), which can detect impurities at concentrations as low as 0.2 atomic $\%$. New metallic phase formation and newly present elements were revealed by the EDS method in several different, separate active spots on the cathode surface, with concentrations ranging from $0.3 \%$ up to 10 or $20 \%$ or more. $\mathrm{Al}$, $\mathrm{Mg}, \mathrm{Br}$, Sr were found at $\sim 0.3 \%$, Rb $\sim 0.4 \%, \mathrm{~S} \sim 1.0 \%, \mathrm{~F} \sim 10 \%, \mathrm{O}>20 \%$, Ni $\sim(0.3-20) \%, \mathrm{Cr}$ $\sim 1.4 \%, \mathrm{Fe} \sim 4.0 \%, \mathrm{Sn}(\sim 0.4$ to $\sim 5.0) \%$ were detected by this method after the experiment and were not in the as-received sample before the experiment. The basic changes are observed in places of microexplosions, micromeltings and structural inhomogeneities. Investigation of the isotopic composition was carried out by Thermal Ionization Mass Spectroscopy (TIMS). Additional elements in a thin surface layer were found by this method when analysis was performed at $1900^{\circ} \mathrm{C}$. The Ti cathode produced excess heat during glow discharge, estimated at 10 to $20 \%$ above input power. This suggests that the heat was caused by the formation of the observed new elements. It is necessary to note that excess heat was created by the processes in a sample having weight of 0.7 gram in a device weighing $5 \mathrm{~kg}$.

At the same time thermal losses with the water cooling of anode, losses through a quartz wall of the discharge chamber and the losses in metal flanges were not taken into account. In the experiments with other cathode materials (including Mo, W and $\mathrm{Zr}$ ) under the same experimental conditions, no excess heat was observed and thermal losses were roughly $40 \%$.
\end{abstract}

\section{INTRODUCTION}

Results from research with Pd cathodes irradiated by deuterium ions in glow discharge were published in previous papers [1-12.] We observed the weak gamma radiation ${ }^{2}$, short-lived neutron bursts $^{1,2,3}$, changes in surface structure and in the elemental and isotopic composition of Pd cathode (with purity $99.99 \%$ and $99.9 \%$ ) $4,5,6,7,8$ under deuterium ion irradiation. After irradiation, autoradiographs (X-ray film placed in contact with the samples) showed blackened areas. Not only were the autoradiographs placed in contact with irradiated Pd samples blackened, but also up to 7 $\mathrm{Pd}, \mathrm{Ti}$ and $\mathrm{Ag}$ foils that were not directly irradiated, but which were located under an irradiated sample were blackened. In Pd samples, elements other than Pd increased by factors of 100 to $10,000{ }^{6-8}$ EDS detected impurity elements in amounts ranging from $0.5 \%$ to $5 \%$, which were not detected in the starting material. ${ }^{5-8}$ In accordance with the radiography analysis results the presence of the radioactive isotopes with various energies of emission on the Pd the cathode after glow discharge experiments had shown both high-energy and low-energy components. ${ }^{5}$ The observed effects can be explained by a fusion-fission reaction on the cathode. That is, by an interaction of palladium with deuterium, and by the subsequent decay into more light elements. The majority of the elements which are detected by this method after irradiation, and which were not present before irradiation, were distributed on the boundaries of the grains and subgrains ${ }^{2,4,5}$ and in local zones. 
The content of additional elements in such places was from about a tenth of a percent up to several percent.

The content of the separate impurity elements in initial samples did not exceed $10^{-3}$ to $10^{-4}$ atomic $\%$ and that amount could not be detected by the microanalysis method. Groups of elements such as Sc, Ti, V; Ag, Cd, In; P, Cl, Br, Ge, As, Kr, Sr, Y, Ru, Xe were found out in Pd after an irradiation by ions of several different types $(\mathrm{D}, \mathrm{H}, \mathrm{Ar}, \mathrm{Ar}+\mathrm{Xe})$, with varying amounts of the elements detected. ${ }^{9}$ The integral sum of all impurity elements in Pd samples after irradiation by D, $\mathrm{H}$, and Ar ions was estimated in the ratio 10:(2-3):1, accordingly. Elements with charge number $\mathrm{Z}=$ $26-31(\mathrm{Fe}, \mathrm{Cu}, \mathrm{Zn}, \mathrm{Ga})$ were observed by the MPA method after preferential irradiation by deuterium ions.

The EDS and radiography results both indicate that nuclear transmutations occur intensively mainly on localized sites (hot spots). ${ }^{5,6,8}$ Different combinations of impurity elements found in different zones on the same samples were observed in the various characteristic spectrums for the same kind of ion ${ }^{7,8}$.

The considerable changes of the isotope ratio ${ }^{10} \mathrm{~B} /{ }^{11} \mathrm{~B} ;{ }^{12} \mathrm{C} /{ }^{13} \mathrm{C} ;{ }^{60} \mathrm{Ni} /{ }^{61} \mathrm{Ni} /{ }^{62} \mathrm{Ni} ;{ }^{40} \mathrm{Ca} /{ }^{44} \mathrm{Ca}$ and ${ }^{90} \mathrm{Zr} /{ }^{91} \mathrm{Zr}$ were observed and were published in paper [6]. The change of the isotope ratio for ${ }^{109} \mathrm{Ag}:{ }^{107} \mathrm{Ag}$ from $1: 1$ in the initial unused Pd up to 3:1 and in some cases 9:1. This was described in Refs. 7 - 9.

In this paper the changes of elemental and isotopic composition in the Ti sample with excess heat during deuterium ion irradiation in a glow discharge plasma is described in greater detail.

\section{EXPERIMENTAL METHOD}

The experimental procedure is described in detail in previous papers [2, 5, and 6]. A Ti (99.93 purity) cathode was irradiated with deuterium ions in a glow discharge, and then later examined. The density of the ion current was 10 to $20 \mathrm{~mA} / \mathrm{cm}^{2}$. The voltage of glow discharge was $300-850 \mathrm{~V}$. The measurement system recorded current, the voltage of the discharge, gas pressure, the velocity of the gas stream, and the flow rate of the cathode cooling water. The temperature at the inlet and outlet of cooling water for both the cathode and the anode was recorded. The program used the inlet and outlet temperatures, flow rate, and input power to compute instantaneous input and output power, and any excess power. The program also keeps track of net input and output energy, and excess energy when present.

The studies on the change of structure and elemental composition in the Ti cathode were carried out with using the scanning electronic microscope (JEOL, model JSM 6460-LV) and energy dispersion spectrometry (EDS) (Oxford Instrument, INCA). The quantitative analysis of the elemental content was performed using INCA software, version 4.02. Acquisition time per location was $\sim 2$ minutes. SEM accelerating voltage was $25 \mathrm{KeV}$. The area of spot analysis was 1 square micron at the site being analyzed; scanned areas were $\sim 25 \times 25$ micron. The elements $\mathrm{O}, \mathrm{F}, \mathrm{S}, \mathrm{Na}$, $\mathrm{Mg}, \mathrm{Al}, \mathrm{Ti}, \mathrm{Cr}$, and Fe were determined by EDS on their $\mathrm{K}-\alpha$ lines; Mo, Br using their L- $\alpha$ lines; and $\mathrm{W}$ using its $\mathrm{M}-\alpha$ line.

The unused sample and a sample subjected to glow discharge in deuterium were analyzed in detail. Places with structural defects (such as flaws, tracks and projections); zones of such new formations such as blisters, craters, and micro-melted spots; needle structures, and typically "pure" sites of a surface without special changes were explored.

Forty-seven sites were analyzed inside new formations and on "pure" sites of the surface of Ti foil after irradiation of deuterium ions and on ten sites on the surface of initial Ti. The most typical places of analyses and the content of additional elements in them with amounts more than $3 \sigma$ are given on the appropriate illustrations and are accompanied by tables.

The thickness of Ti foil was $0.05 \mathrm{~mm}$; the titanium purity was $99.93 \%$. Table 1 shows the impurities in the starting material, from the manufacturer's certified data taken by X-ray diffraction. 


\section{RESULTS}

TABLE 1. IMPURITIES IN THE Ti FOIL STARTING MATERIAL

$\begin{array}{lcl}\text { Element } & \text { Content, ppm } & \text { Atomic, } \% \\ \mathrm{Al} & 30 & 3 \times 10^{-3} \\ \mathrm{Fe} & 20 & 2 \times 10^{-3} \\ \mathrm{Ca} & 10 & 1 \times 10^{-3} \\ \mathrm{Mn} & 8 & 8 \times 10^{-4} \\ \mathrm{~V} & 2 & 2 \times 10^{-4} \\ \Sigma & 70 & 7 \times 10^{-3} \\ \mathrm{Ti} & & 99.93\end{array}$

Samples after glow discharge experiments usually have the largest changes in structure and chemical element composition on the boundary between the irradiated and screened zones.

Fig. 1 shows a series of three places: tracks of microexplosions on the boundary of the irradiated and unirradiated areas. A typical example of these places is shown on Fig. 2 and 3 in more detail. There appears to be pair formations of the greater and smaller sizes located $\sim 100$ microns apart. All these formations, along with the micro craters, were carefully analyzed for chemical element composition. The composition of groups of the impurity elements in every formation is shown in Tables 1-6 below. The back side of the cathode has also been analyzed, but it did not reveal any changes from the original, as-received impurities. The same can be said for sites that were screened from ion irradiation.

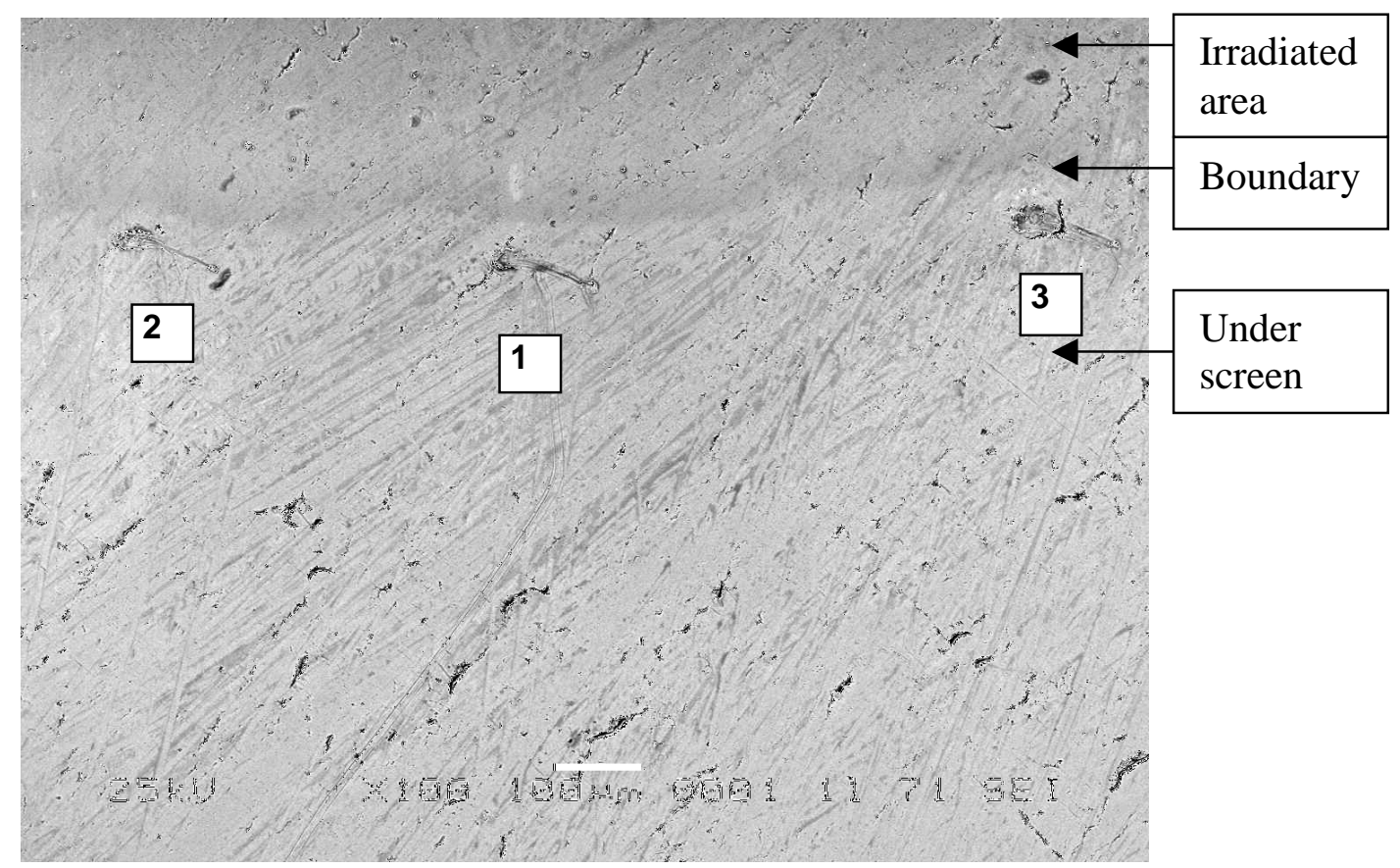

Fig. 1. Surface of Ti foil on the boundary of the irradiated and unirradiated zones (the irradiated area is darker gray). 


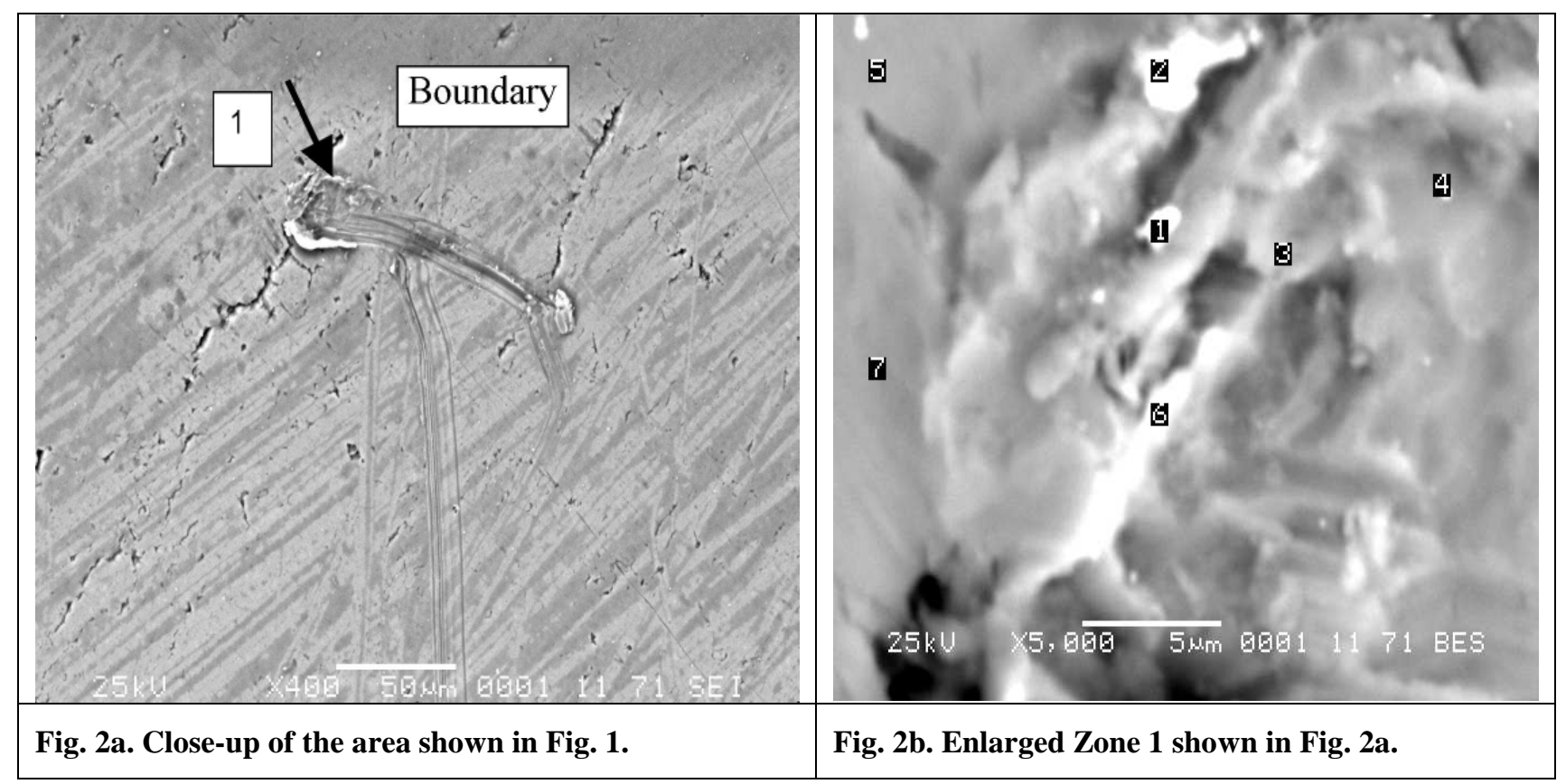

The composition of chemical elements in every area that was analyzed is shown in Table 2 . Columns 1 - 6 of Table 2 are the results of the elemental analysis that were carried out for a series of new formations on the boundary between the irradiated titanium and Mo screen, which are shown in Fig. 1 and magnified in Fig. 2 and 3.

\section{TABLE 2. RESULTS OF THE CHEMICAL ELEMENTAL ANALYSES BY EDS METHOD IN} 23 SELECTED SITES

\begin{tabular}{|c|c|c|c|c|c|c|c|c|c|c|c|}
\hline \multirow{2}{*}{ Element } & \multicolumn{11}{|c|}{ Site } \\
\hline & 1 & 2 & 3 & 4 & 5 & 6 & 7 & 8 & 9 & 10 & 11 \\
\hline 0 & $23.41 \pm 0.92$ & $18.59 \pm 1.5$ & $26.9 \pm 1.2$ & & $22.0 \pm 1.0$ & & $53.61 \pm 0.8$ & $30.22 \pm 2$ & $37.4 \pm 1.0$ & $20.87 \pm 1$ & $17 \pm 1.0$ \\
\hline Al & $0.43 \pm 0.09$ & & $0.24 \pm 0.1$ & $0.47 \pm 0.1$ & $0.25 \pm 0.1$ & & $0.37 \pm 0.08$ & $0.16 \pm 0.07$ & $0.32 \pm 0.1$ & $0.54 \pm 0.1$ & $0.6 \pm 0.1$ \\
\hline $\mathrm{F}$ & $5.59 \pm 0.65$ & $6.63 \pm 0.83$ & $36.72 \pm 1.0$ & & $8.6 \pm 1.0$ & $8.11 \pm 0.6$ & $6.79 \pm 0.7$ & $15.8 \pm 1.1$ & $16.9 \pm 1.3$ & $5.04 \pm 1.0$ & $7.7 \pm 1.0$ \\
\hline $\mathrm{Fe}$ & $0.52 \pm 0.10$ & $0.89 \pm 0.08$ & & & & & $0.17 \pm 0.04$ & & & & \\
\hline Na & & & & & $0.39 \pm 013$ & & & $0.41 \pm 0.2$ & $0.47 \pm 0.15$ & & \\
\hline $\mathrm{S}$ & & $1.89 \pm 0.2$ & $1.08 \pm 0.1$ & & $1.08 \pm 0.1$ & $0.27 \pm 0.07$ & & & & & \\
\hline $\mathrm{Ni}$ & & $0.25 \pm 0.08$ & & & & & & & & & \\
\hline Mg & & & $0.26 \pm 0.11$ & & $0.24 \pm 0.1$ & & & & & & \\
\hline \multicolumn{12}{|l|}{$\mathbf{R b}$} \\
\hline $\mathrm{Cr}$ & & $0.36 \pm 0.1$ & & & & & & & & & \\
\hline \multicolumn{12}{|l|}{ Sn } \\
\hline $\mathrm{Br}$ & & & & & & $0.28 \pm 0.09$ & & & & & \\
\hline $\mathrm{Si}$ & & & & & & & $0.39 \pm 0.08$ & & & & \\
\hline \multicolumn{12}{|l|}{$\mathrm{Sr}$} \\
\hline \multicolumn{12}{|l|}{ Hf } \\
\hline \multicolumn{12}{|l|}{ Co } \\
\hline \multicolumn{12}{|l|}{$\mathrm{Ca}$} \\
\hline \multicolumn{12}{|l|}{ Mn } \\
\hline \multicolumn{12}{|l|}{ V } \\
\hline $\mathrm{Ti}$ & $59.49 \pm 1$ & $62.3 \pm 1.1$ & $62.46 \pm 1.2$ & $97.36 \pm 0.4$ & $67.7 \pm 1.2$ & $90.78 \pm 0.7$ & $33.47 \pm 0.7$ & $50.91 \pm 1.0$ & $41.67 \pm 1.0$ & $62.25 \pm 1$ & $54.8 \pm 1$ \\
\hline Mo & $9.85 \pm 0.5$ & & & & $0.13 \pm 0.5$ & & $1.21 \pm 0.1$ & & & $9.3 \pm 0.5$ & $19.9 \pm 1$ \\
\hline
\end{tabular}


TABLE 2, CONTINUED

\begin{tabular}{|c|c|c|c|c|c|c|c|c|c|c|c|c|}
\hline \multirow{2}{*}{ Element } & \multicolumn{12}{|c|}{ Site } \\
\hline & 12 & 13 & 14 & 15 & 16 & 17 & 18 & 19 & 20 & 21 & 22 & 23 \\
\hline $\mathrm{O}$ & & & & & $18.1 \pm 0.4$ & $45.0 \pm 1.0$ & $25.42 \pm 2$ & $63.14 \pm 0.8$ & $68.8 \pm 1.0$ & $60.1 \pm 1$ & & \\
\hline $\mathrm{Al}$ & & & & & & & & & & & & $0.4 \pm 0.2$ \\
\hline $\mathrm{F}$ & & & & & & $2.99 \pm 0.68$ & & & & & & \\
\hline $\mathrm{Fe}$ & $14.23 \pm 0.6$ & & & $6.46 \pm 0.43$ & $16.0 \pm 0.3$ & $0.19 \pm 0.05$ & $6.46 \pm 0.43$ & & & $2.1 \pm 0.3$ & & \\
\hline $\mathrm{Na}$ & & & & & & $0.61 \pm 0.12$ & & $0.67 \pm 0.14$ & & & & $1.3 \pm 0.3$ \\
\hline $\mathrm{S}$ & & & & & & & & & & & & \\
\hline $\mathrm{Ni}$ & & & & $21.43 \pm 0.9$ & $47.17 \pm 0.5$ & $0.37 \pm 0.05$ & & & & & & \\
\hline Mg & & & & & & & & & & & & \\
\hline$\underset{R b}{R}$ & & $0.67 \pm 0.2$ & & & & & & & & & & \\
\hline $\mathrm{Cr}$ & $2.42 \pm 0.34$ & & & & & & & & & & & \\
\hline Sn & & & & & & & & & & $4.9 \pm 0.2$ & $0.4 \pm 0.2$ & \\
\hline $\mathrm{Br}$ & & & & & & & & & & & & \\
\hline $\mathrm{Si}$ & & & & & & & & $1.53 \pm 0.1$ & $2.95 \pm 0.14$ & & & \\
\hline $\mathrm{Sr}$ & & & & & & & & & & & & $0.3 \pm 0.2$ \\
\hline Hf & & $4.76 \pm 0.3$ & $1.43 \pm 0.2$ & & & & & & & & & \\
\hline Co & & & & $2.57 \pm 0.4$ & $6.06 \pm 0.28$ & & & $2.57 \pm 0.4$ & & & & \\
\hline $\mathbf{T i}$ & $83.3 \pm 0.7$ & \pm 1.1 & $88.5 \pm 1.2$ & $97.36 \pm 0.4$ & $67.7 \pm 1.2$ & $50.41 \pm 0.7$ & $44.13 \pm 1.13$ & $31.26 \pm 0.7$ & $20.35 \pm 0.6$ & $32.9 \pm 1$ & $54.8 \pm 1$ & $98.0 \pm 0.6$ \\
\hline Mo & $9.85 \pm 0.5$ & & & & $0.13 \pm 0.5$ & $0.43 \pm 0.1$ & & $3.41 \pm 0.2$ & $7.75 \pm 0.6$ & & $19.9 \pm 1$ & \\
\hline
\end{tabular}

Notes:

1. The elements that appeared as a result after sputtering of the previous samples were not included in the tables.

2. Mo comes from sputtering of the screen that holds the sample.

As can be seen here, the combination of elements found in different spots that were analyzed in a $\sim 1$ cubic micron sample may vary, but usually some elements are found in common. For example, the row of selected spots contained such impurities as $\mathrm{O}, \mathrm{F}, \mathrm{Al}, \mathrm{Fe}$, and $\mathrm{Mg}$. The increased size of the formation from zone 3, Fig. 1, which can be characterized as a microexplosion zone or a zone of local melting, is shown on Fig. 2 and 3. The analysis results of the area $50 \times 50$ micron $\left(2.5 \times 10^{-3} \mathrm{~mm}^{2}\right)$ are placed in column 6 .

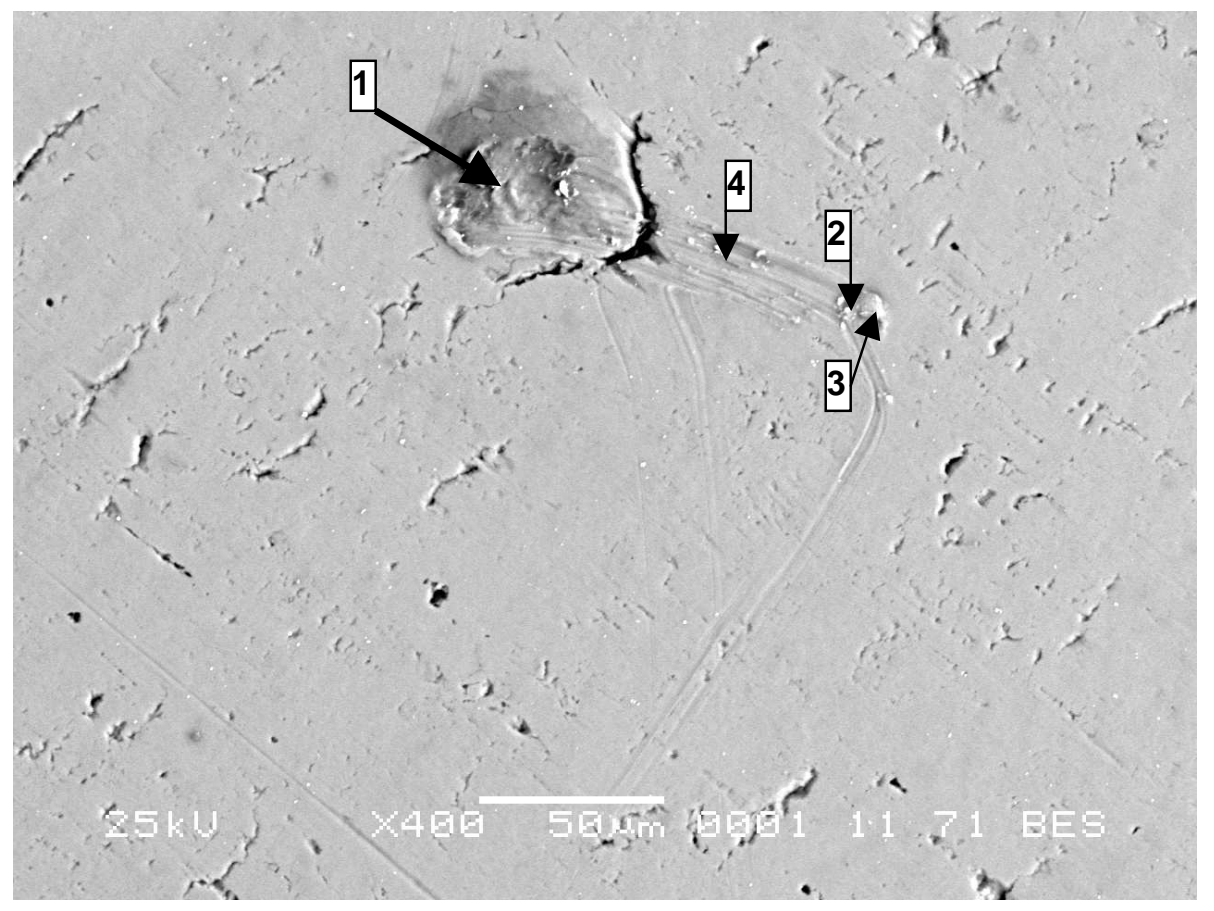

Fig. 3. The locally melted zone near Ti-Mo screen boundary. 
The combination of the main impurity elements in the examined zones is variable. Most of the analyzed areas in this series contained F: $\mathrm{F}$ was found in all 7 areas; $\mathrm{Al}$ in 6 areas; $\mathrm{O}$ in 4 areas; $\mathrm{Na}$ in 2; and $\mathrm{S}, \mathrm{Br}, \mathrm{Mg}$ were found in only one area. The content and combinations of impurity elements is quantitatively reproducible when the areas analyzed are situated in the new formations, for example in Fig. 2, zone 1. Similar elements and combinations of elements were found in Fig. 4, areas 1-3, and in Fig. 5, areas 1-3. In Table 2, the elements under columns 10 and 11, Na, Si and Al, were found in areas 1 through 4.

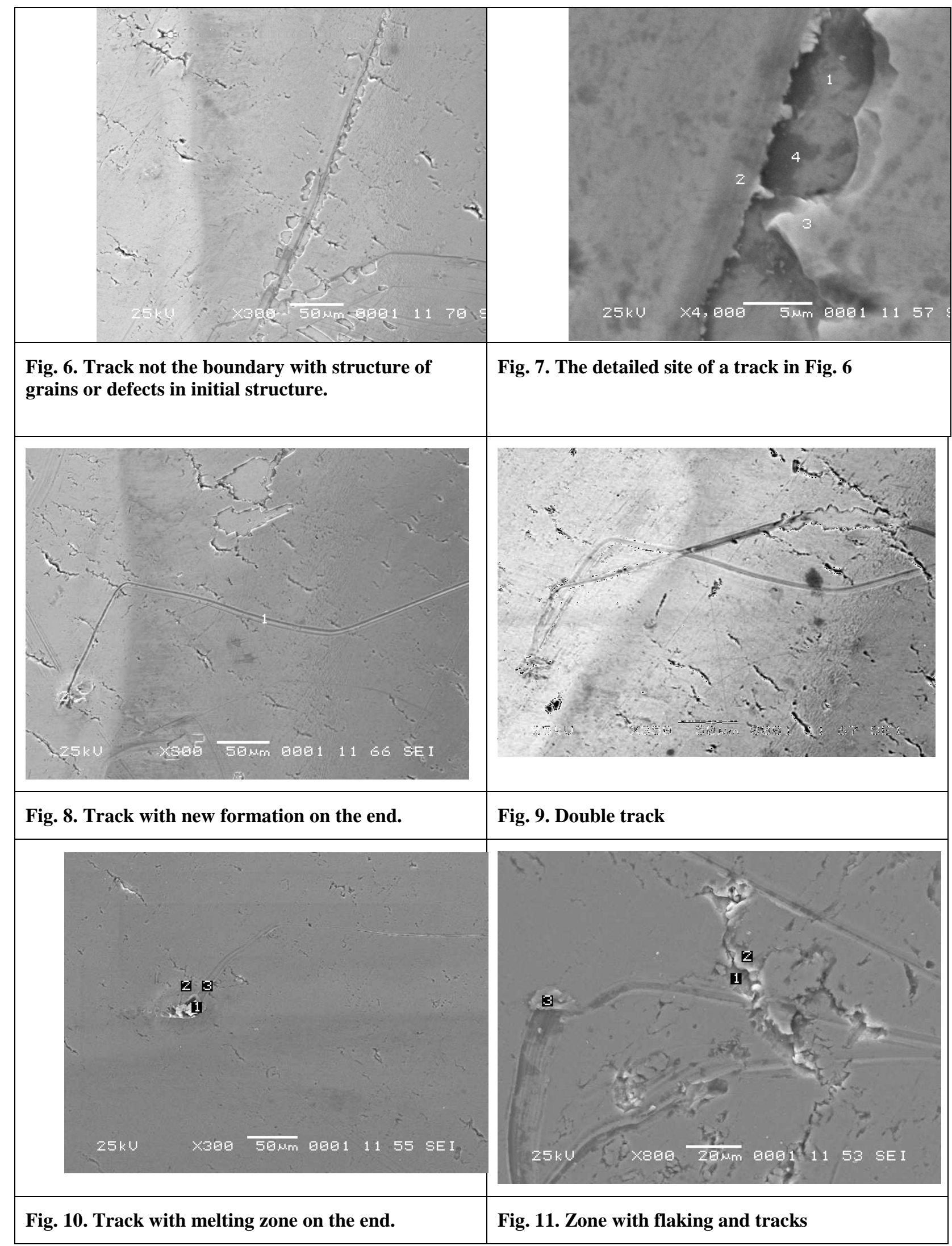




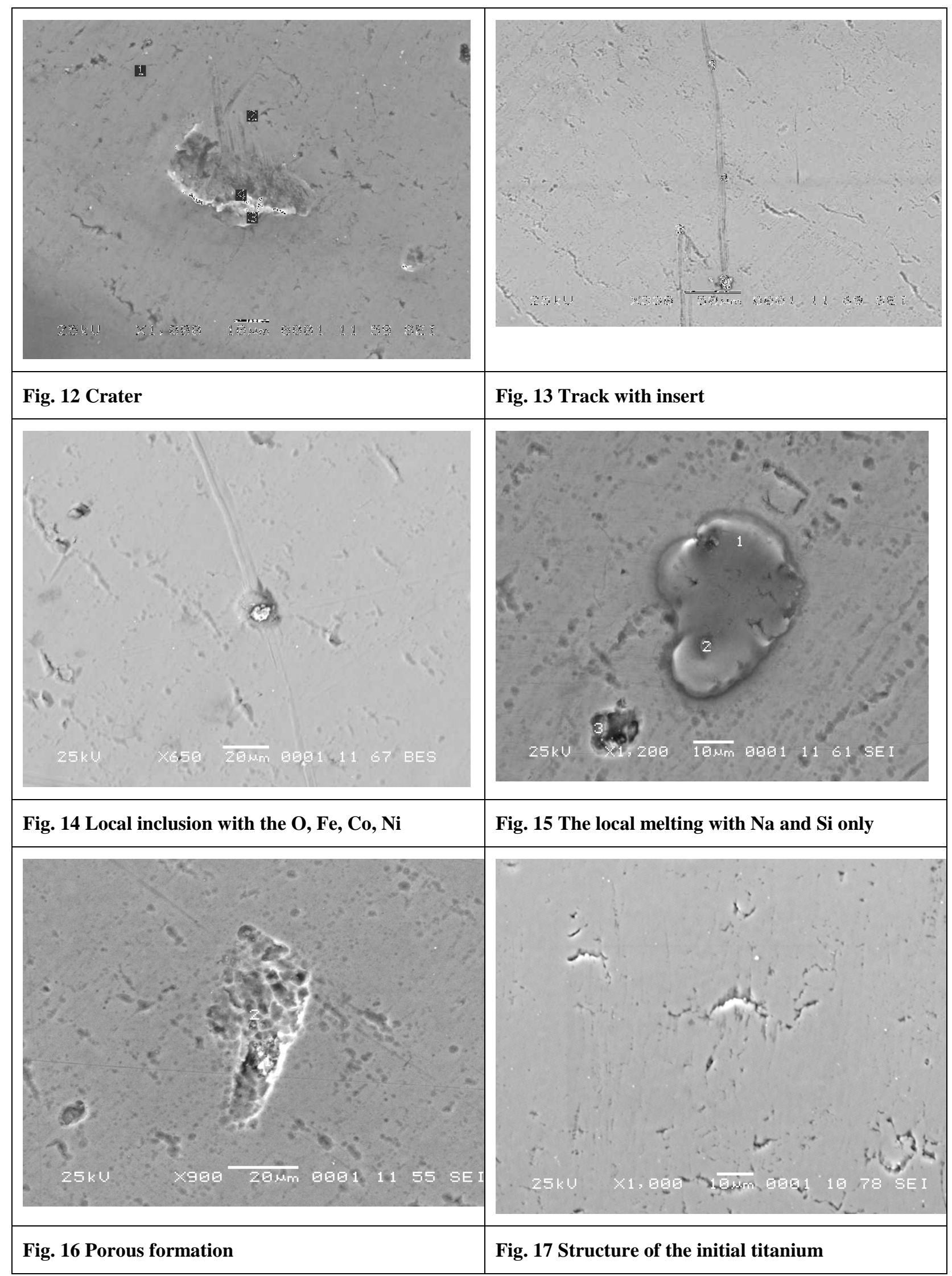

Some tracks which appeared after the experiment and were not bound with the grain structure of the Ti were also analyzed. Areas with small amounts of $\mathrm{Na}, \mathrm{Mg}, \mathrm{Al}$ and $\mathrm{Si}$ and $\mathrm{Cr}, \mathrm{Fe}$ with content $>3 \sigma$ were revealed in points of zone 1 on Fig. 8. The typical element composition in the field of a track Fig. 8 is given in column 12. 
Most of the additional elements were found in such structural defects, as zones of microexplosions, in the places of a new phase formation, of tracks (Fig. 9) and of destroyed surface structure.

The tracks usually were observed near places were new phase formations occurred (Fig. 10). As shown in Fig. 7 - 9, these formations were sometimes convex and sometimes concave. The tracks were not bound with the grain boundaries on Ti surface. The tracks may be caused by a unipolar arc in the glow discharge moving along structural flaws, and being a consequence of overvoltages in the areas of microflaws, oxide films and phase inclusions. ${ }^{13}$ Formation of pair defects of the greater and smaller sizes (Fig. 12,15) was typical, as noted earlier (Fig. 1-3). No impurity elements were found on the undisturbed areas of the Ti surface. For example, the impurity elements were not found in Fig. 12, areas 1 and 2. The combination of $\mathrm{Fe}, \mathrm{Ni}$, Co does not correspond to any possible penetration of these elements from the stainless steel water-cooled sample holder. $\mathrm{Rb}$ and $\mathrm{Hf}$ are not present in any of the cell components. Sn also could not get onto the cathode from the surrounding medium. $\mathrm{Na}$ and $\mathrm{Si}$ in small amounts were found in the defect zone (Fig. 17).

Impurity elements were found in 22 cases from 47 areas on the analyzed surface of $\mathrm{Ti}$ in regions that had been irradiated (Table 2). The amount of $\mathrm{Al}$ and Fe (Table 3) detected increased by factors of 100 to 1000. The comparison of the average amount of main impurity elements in an initial material and after experiment was made. The basic impurity elements with the concentrations exceeding an error of measuring more $3 \sigma$ were placed in Table 3, column 3. Column 2 shows the number of points at which each element was observed. The elements present before the experiment are shown in column 4.

TABLE 3. MAIN IMPURITY ELEMENTS IN Ti AFTER EXPERIMENTS IN DEUTERIUM GLOW DISCHARGE DETECTED BY EDS

\begin{tabular}{|c|c|c|c|}
\hline Element & $\begin{array}{l}\text { Number of spots on } \\
\text { the cathode where } \\
\text { this element was } \\
\text { found } *\end{array}$ & $\begin{array}{l}\text { The amount of the } \\
\text { element after the } \\
\text { experiment, in atomic } \\
\% * *\end{array}$ & $\begin{array}{l}\text { The amount of the } \\
\text { element before the } \\
\text { experiment, in atomic } \%\end{array}$ \\
\hline 1 & 2 & 3 & 4 \\
\hline $\mathrm{O}$ & 12 & $27 \pm 1.2$ & \\
\hline $\mathrm{Al}$ & 9 & $0.33 \pm 0.1$ & $3 \times 10^{-3}$ \\
\hline $\mathrm{F}$ & 6 & $10 \pm 0.56$ & \\
\hline $\mathrm{Fe}$ & 6 & $4.05 \pm 0.2$ & $2 \times 10^{-3}$ \\
\hline $\mathrm{Na}$ & 4 & $0.70 \pm 0.3$ & \\
\hline$S$ & 3 & $1.08 \pm 0.13$ & \\
\hline $\mathrm{Ni}$ & 2 & $10.8 \pm 0.36$ & \\
\hline $\mathrm{Mg}$ & 2 & $0.26 \pm 0.15$ & \\
\hline $\mathrm{Rb}$ & 2 & $0.44 \pm 0.12$ & \\
\hline $\mathrm{Cr}$ & 2 & $1.39 \pm 0.21$ & \\
\hline Sn & 2 & $2.7 \pm 0.14$ & \\
\hline $\mathrm{Br}$ & 1 & $0.28 \pm 0.1$ & \\
\hline $\mathrm{Si}$ & 1 & $0.39 \pm 0.09$ & \\
\hline $\mathrm{Sr}$ & 1 & $0.33 \pm 0.25$ & \\
\hline $\mathrm{Hf}$ & 1 & $4.76 \pm 0.09$ & \\
\hline $\mathrm{Co}$ & 1 & $2.57 \pm 0.3$ & \\
\hline $\mathrm{Ca}$ & & & $1 \times 10^{-3}$ \\
\hline $\mathrm{Mn}$ & & & $8 \times 10^{-4}$ \\
\hline $\mathrm{V}$ & & & $2 \times 10^{-4}$ \\
\hline $\mathrm{Ti}$ & & & 99.93 \\
\hline
\end{tabular}

* Number of spots on the cathode surfaces with the element measured at $3 \sigma$ or better. 
** The average concentration for all analyzed spots containing this element.

As shown in Table 3, $\mathrm{Cr}, \mathrm{Sn}, \mathrm{Rb}$ were revealed in two spots on the cathode, $\mathrm{Na}$ in four spots, $\mathrm{Fe}, \mathrm{Al}$ in six, and oxygen in 12 spots.

The results at the analysis of Ti as received measured by TIMS is tabulated in Table 4.

TABLE 4. THE BASIC IMPURITY ELEMENTS in Ti BEFORE and AFTER EXPERIMENTS in DEUTERIUM GLOW DISCHARGE ANALYSED by TIMS

\begin{tabular}{|c|c|c|c|c|c|}
\hline Masses & Element & $\begin{array}{l}\mathrm{N}_{\mathrm{a}}, \mathrm{cps}, 1900^{\circ} \mathrm{C} \\
\text { after experiment }\end{array}$ & $\begin{array}{l}\mathrm{N}_{\mathrm{ah}}, \mathrm{cps}, 1950^{\circ} \mathrm{C} \\
\text { after experiment }\end{array}$ & $\begin{array}{l}\mathrm{N}_{\mathrm{b}}, \mathrm{cps}, 1900^{\circ} \mathrm{C} \\
\text { before experiment }\end{array}$ & $\begin{array}{l}\Delta=\mathrm{N}_{\mathrm{a}}-\mathrm{N}_{\mathrm{b}} \\
\mathrm{cps}, 1900^{\circ} \mathrm{C}\end{array}$ \\
\hline 1 & 2 & 3 & 4 & 5 & 6 \\
\hline 27 & $\mathrm{Al}$ & 100,000 & & 10,000 & 90,000 \\
\hline $84,86,88$ & $\mathrm{Sr}$ & 2,070 & 1950 & 150 & 1,970 \\
\hline $42,43,44$ & $\mathrm{Ca}$ & 51,000 & & 470 & 50,530 \\
\hline $\begin{array}{l}130,132,134,1 \\
35,136,137, \\
138\end{array}$ & $\mathrm{Ba}$ & 50,620 & & 790 & 49,900 \\
\hline $\begin{array}{l}142,143,144, \\
145,146,148, \\
150\end{array}$ & $\mathrm{Nd}$ & 435 & & 30 & 405 \\
\hline $\begin{array}{l}155,156 \\
157,158\end{array}$ & $\mathrm{Gd}$ & 1,500 & & 85 & 1,415 \\
\hline $206,207,208$ & $\mathrm{~Pb}$ & 510 & & 60 & 450 \\
\hline & $\Sigma$ & 211,240 & 48,670 & 11,930 & 198,160 \\
\hline
\end{tabular}

Column 3: $\mathbf{N}_{\mathbf{a}}$-the count per second for analysis temperature $1900^{\circ} \mathrm{C}$ after experiment

Column 4: $\mathbf{N}_{\mathbf{b}}$ the count per second for analysis temperature $1950^{\circ} \mathrm{C}$ after experiment

Column 5: $\mathbf{N}_{\mathrm{ah}}$ the count per second for analysis temperature $1900^{\circ} \mathrm{C}$ before experiment

Column $6 \Delta: \mathbf{N}_{\mathbf{a}}-\mathbf{N}_{\mathbf{b}}$-the difference of cps after and before experiment for analysis temperature $1900^{\circ} \mathrm{C}$

- $\mathrm{Sr}-87$ is equal in mass to $\mathrm{Rb}-87(85,87)$, and a lot of it was found in the tungsten cathode.

- A decrease in Fe-56 by factors of up to 100 was observed. Fe-57 had a slight change in quantity compared to the initial sample. BUT :

- Mass 55 increased strongly (by a factor of 40).

- Mass 55 is Mn or Fe-55 (electron capture).

- Mn was not found by the EDX method. Fe was found by the EDX method to be $4 \pm 0.2 \%$. This is a very interesting change, and it may be highly significant! It may indicate the mechanism for $\mathrm{Fe}-56$ to $\mathrm{Fe}-55$ transformation.

- The Ca-40 isotope was found in large quantities during the analysis of the initial sample and after the experiment. This is the reason it was excluded from Table 4.

We observed $\mathrm{Al}, \mathrm{Ca}, \mathrm{Sr}, \mathrm{Ba}, \mathrm{Nd}, \mathrm{Ga}, \mathrm{Pb}$ and small amounts of additional elements in the thin surface layers of the Ti. The amount of the impurity elements in the thin surface layer $(\sim 100$ to 150 Angstroms) observed by TIMS is considerably greater than the amounts measured by EDX. The total amount in counts per second was $\sim 2 \times 10^{5}$ cps. Elements such as $\mathrm{Al}$ and $\mathrm{Sr}$ were also observed by the EDX method $\sim 1$ micron below the surface. Presumably the most of the transmutation reaction takes place in the thin surface layer under low energy glow discharge.

It must be noted that that we study the local spots on the cathode by EDX, and integral content on the surface of the cathode in small volumes $(1.5 \pm 0.5 \mathrm{~mm} \times 20 \mathrm{~mm} \times 100$ microns $)$ by TIMS. Moreover the TIMS method can resolve in Angstrom units near the surface, especially for heavy elements. The biggest changes in elemental composition were always observed near the boundary of irradiated and unirradiated areas. This was one reason why various methods of 
spectroscopy yield different levels of some elements. The cathode of the TIMS mass spectrometer itself was made from Re (masses 85 and 87), so we did not try to measure Sr-87.

\section{TABLE 5. ISOTOPIC SHIFT IN Ti AFTER GLOW DISCHARGE}

\begin{tabular}{|l|l|l|l|l|l|l|l|l}
\hline Mass & Element & $\begin{array}{l}\text { Abundance, } \\
\%\end{array}$ & $\begin{array}{l}\mathrm{CPS} \\
1900^{\circ} \mathrm{C} \\
\text { experiment }\end{array}$ & $\begin{array}{l}\mathrm{CPS} \\
1900^{\circ} \mathrm{C} \\
\text { initial }\end{array}$ & $\begin{array}{l}\text { Isotopes ratio } \\
\text { (Abundance and } \\
\text { experiment) }\end{array}$ & $\begin{array}{l}\text { Abundance of } \\
\text { isotopes ratio / } / \text { The increasing } \\
\text { experiment of } \\
\text { isotopes ratio }\end{array}$ & $\begin{array}{l}\Delta, \mathrm{cps} \\
\text { experiment, } \\
\text { times }\end{array}$ & \\
\hline 1 & 2 & 3 & 4 & 6 & 7 & 8 & 9 & 10 \\
\hline 40 & $\mathrm{Ca}$ & 96.9 & $1,250,000$ & $>10,000$ & $\begin{array}{l}40 / 44=48.4 \text { abun. } \\
40 / 44=31 \text { exper. }\end{array}$ & 1.56 & & \\
\hline 42 & $\mathrm{Ca}$ & 0.65 & 10.000 & 150 & $\begin{array}{l}40 / 42=161 \text { abun. } \\
40 / 42=125 \text { exper. }\end{array}$ & 1.3 & 66.7 & $9750 \pm 50$ \\
\hline & & & & & & & & \\
\hline 43 & $\mathrm{Ca}$ & 0.135 & 1,000 & 120 & $\begin{array}{l}44 / 4314.8 \text { abun. } \\
44 / 43=40 \text { exp. }\end{array}$ & 0.37 & 9.8 & $880 \pm 50$ \\
\hline 44 & $\mathrm{Ca}$ & 2.0 & 40,000 & 200 & $\begin{array}{l}44 / 42=3.3 \text { abun. } \\
44 / 42=4 \text { exper. }\end{array}$ & 0.82 & 200 & 38800 \\
\pm 50
\end{tabular}

\section{HEAT EFFECT}

Diagrams illustrating the excess heat effect in a Ti sample in a quartz cell with cooling cathode and anode are shown in Fig. 16.

The heat efficiency (COPE) presented on Fig. 16 ranged from 10\% up to 30\% within 2.5 hours, and excess energy output in these conditions was $\sim 1$ watt, with 5 watts of input power.

It should be noted that the excess heat effect was observed in the Ti sample with 0.7 gram weight and that the weight of the working chamber was $5 \mathrm{~kg}$. The excess heat was determined without taking into account the losses in anode cooling by flowing water, and without taking into account heat losses due to the heat transfer through the $785 \mathrm{~cm}^{2}$ area quartz tube wall of the working chamber, or the heat losses through metal flanges of the working chamber.

The excess heat effects were observed repeatedly even after the equipment was turned on and off several times. Typical process in the same glow discharge parameters with other cathode materials showed the negative amount $\mathrm{P}_{\mathbf{x}}=\left(\mathrm{P}_{\text {out }}-\mathrm{P}_{\text {in }}\right) \sim 1$ watt and COPE $=\left(\mathrm{P}_{\text {out }}-\mathrm{P}_{\text {in }}\right) / \mathrm{P}_{\text {in }} \sim-(0.2-$ 0.5). This indicates that the losses for $\mathrm{Zr}$ and Mo were 20 to $50 \%$. 


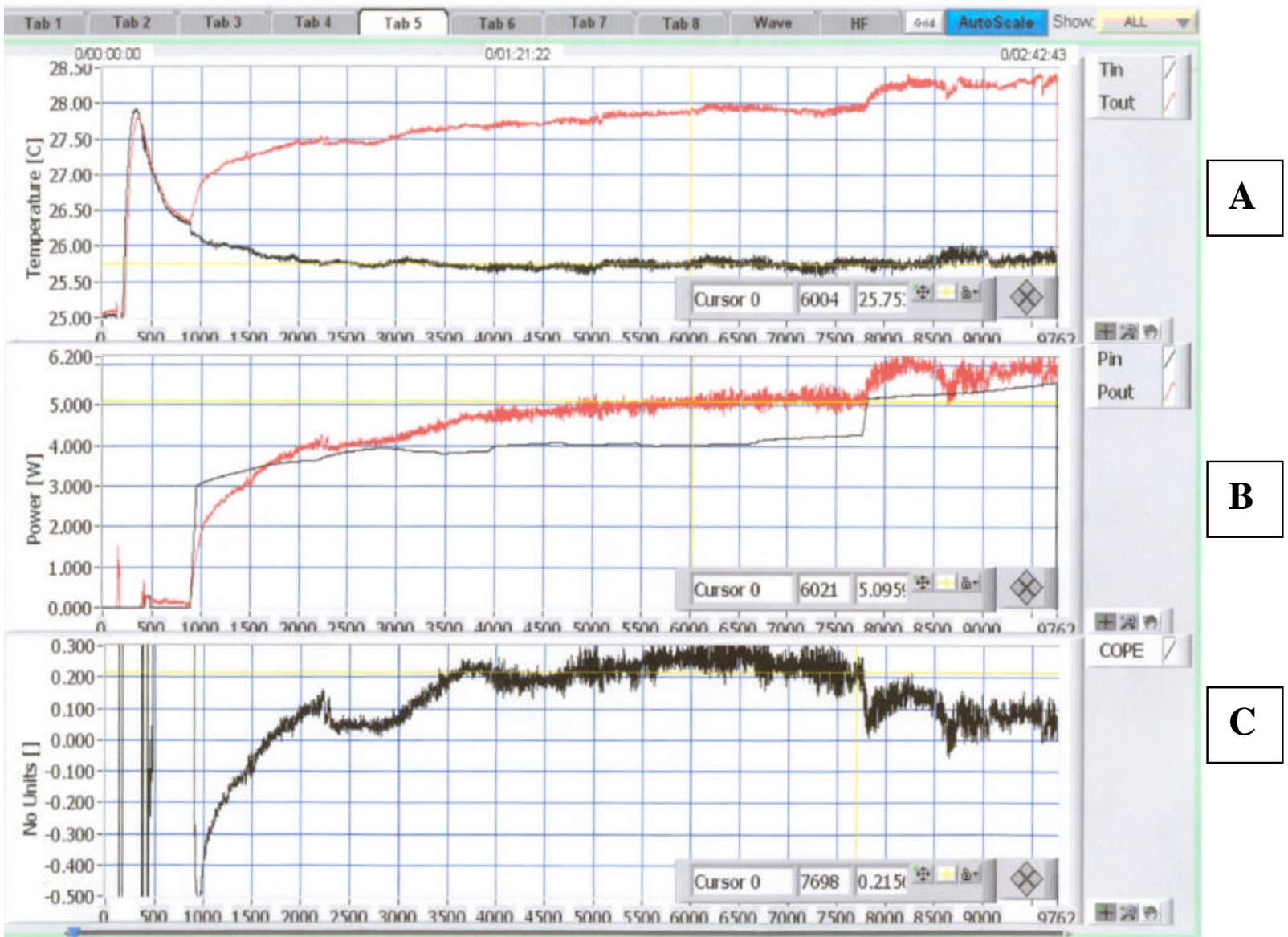

Fig. 16 A. $\mathbf{T}_{\mathrm{in}}, \mathbf{T}_{\text {out }}$ - temperature of input cooling water in cathode and of output cooling water from cathode, ${ }^{0} \mathrm{C}$.

Fig. 16 B. $\mathbf{P}_{\text {in }}, \mathbf{P}_{\text {out }}$ - input energy and output energy from the water-cooling system, in watts.

Fig. 16 C. COPE $=\left(P_{\text {out }}-P_{\text {in }}\right) / P_{\text {in }}($ an approximate measure of efficiency $)$

\section{DISCUSSION}

Many areas on the irradiated surface of the Ti sample that were analyzed contained only titanium. Outside of the unusual new structures found on the surface, impurity elements were not detected at the limits of sensitivity of the equipment.

Excess content of the impurity elements on the irradiated titanium surface were found in 20 cases from 47 analyzed places. The amount of the impurity elements in the comparison with an initial material was more from 10 up to 1000 times, and from a few tenths of a percent up to several percent. The total content of the impurity elements in an initial sample did not exceed $7 \times 10^{-3}$ atomic $\%$. The redistribution of the elements is insignificant.

Some chemical elements found on the sample surface might be the result of cathode sputtering and of sprayed metal precipitation from the cell components, cathode holder, and cathode screen, such as, for example, Mo from the screen. However it should be noted that:

- The Mo screen was carefully cleaned before each experiment by chemical etching and washing;

- Most elements given in the table were absent from all of the cell components;

- Tracks of $\mathrm{Al}$ and $\mathrm{Fe}$ in $2 \times 10^{-3}$ to $3 \times 10^{-3}$ atomic \% certificated in Ti were not found by EDS in the unused samples of $\mathrm{Ti}$;

- There were no sites with a similar chemical composition and concentration of the impurity elements on the back of the sample, or under the area screened from glow discharge.

Let us assume there was a redistribution or migration of these chemical elements ( $\mathrm{Al}$ and $\mathrm{Fe}$ ) in samples under ion bombardment in glow discharge plasma, and also that the element 
segregation by diffusion is possible. We might also assume that $\mathrm{Fe}, \mathrm{Cr}$, $\mathrm{Ni}$ in areas where microexplosions occurred could be a result of transmission of these chemical elements from the stainless steel substrate of the heat sink through the foil during the formation of micro-arcs. However, the EDS analysis did not reveal such segregations on the back of the Ti sample.

The existence of $\mathrm{Hf}, \mathrm{Rb}$, and $\mathrm{Sn}$ in new formations is difficult to explain. Some chemical elements could be a result of fusion reactions and second-order decay under excitation of microplasma discharges on the surface of defects (including unevenness, oxide films or inclusions). The presence of local sites in the blackening on x-ray films (hot points) took place in contact to samples of the titanium, silver and palladium after deuterium irradiation early. It was shown in refs 5 and 7.

On the basis of the law of conservation of energy and the exothermic reaction it is was possible to assume the following reactions:

$$
\begin{aligned}
& { }_{22} \mathrm{TI}^{48}+4{ }_{1} \mathrm{D}^{2} \rightarrow{ }_{20} \mathrm{Ca}^{44}+{ }_{6} \mathrm{C}^{12}+35.5 \mathrm{MeV} \\
& { }_{22} \mathrm{TI}^{48}+2_{1} \mathrm{D}^{2} \rightarrow{ }_{16} \mathrm{~S}^{32}+{ }_{8} \mathrm{O}^{18}+4 \mathrm{MeV} \\
& { }_{22} \mathrm{Ti}^{48}+{ }_{6} \mathrm{C}^{12} \rightarrow{ }_{27} \mathrm{Co}^{59}+\mathrm{p}+6.45 \mathrm{MeV} \\
& { }_{22} \mathrm{Ti}^{48}+{ }_{6} \mathrm{D}^{2} \rightarrow{ }_{27} \mathrm{Co}^{59}+\mathrm{p}+85 \mathrm{MeV} \\
& 2_{22} \mathrm{Ti}^{46} \rightarrow{ }_{16} \mathrm{~S}^{32}+{ }_{28} \mathrm{Ni}^{60}+2.239 \mathrm{MeV} \\
& 2_{22} \mathrm{Ti}^{47} \rightarrow{ }_{16} \mathrm{~S}^{32}+{ }_{28} \mathrm{Ni}^{62}+2.798 \mathrm{MeV} \\
& { }_{222} \mathrm{Ti}^{48} \rightarrow{ }_{16} \mathrm{~S}^{32}+{ }_{28} \mathrm{Ni}^{64}+3.863 \mathrm{MeV} \\
& { }_{222} \mathrm{Ti}^{46} \rightarrow{ }_{26} \mathrm{Fe}^{56}+{ }_{16} \mathrm{~S}^{34}+2.289 \mathrm{MeV} \\
& { }_{222} \mathrm{Ti}^{48}+{ }_{6} \mathrm{C}^{12} \rightarrow{ }_{26} \mathrm{Fe}^{56}+{ }_{24} \mathrm{Cr}^{52}+19.043 \mathrm{MeV} \\
& { }_{222} \mathrm{Ti}^{50}+{ }_{6} \mathrm{C}^{12} \rightarrow{ }_{50} \mathrm{Sn}^{112}+46.498 \mathrm{MeV}
\end{aligned}
$$

In the EDS analysis, carbon was not taken into account, because carbon was always present in the electronic microscope.

The likelihood of a transformation of a major collection of nuclei was considered in a series of papers as transitions from one state to another. ${ }^{15-16}$ It is not clear what the mechanism of the transition might be.

The formation of micro discharges (unipolar arcs) was observed during the impulsive discharges and was studied by V. A. Ivanov et al. ${ }^{13}$ The craters and local sites of a remelted material were shaped on a surface of the cathode during these processes.

The formation of craters from micro explosions and local sites of the fused metal was noted for the similar processes in glow discharge plasma. Formation of pairs of craters separated by 100 microns suggests that these formations were created simultaneously.

The result with appearing of similar additional chemical elements on Pd cathode was observed after electrolysis with plasma discharge in the paper ${ }^{14}$ also.

The similarity of the resulting effects in the various processes (glow discharge, electrolysis with plasma discharge and other methods of excitation) could all be the same phenomenon.

The opportunity of reactions with six deuterium atoms (ions) of the simultaneously participation was shown in the paper of Y. Iwamura: ${ }^{17}$

$$
{ }_{56} \mathrm{Ba}^{138} \rightarrow{ }_{62} \mathrm{Sm}^{150} ;{ }_{56} \mathrm{Ba}^{137} \rightarrow{ }_{62} \mathrm{Sm}^{149} .
$$

But it could be fusion with one carbon atom (ion).

Detection of the increased occurrence of anomalous elements in phase inclusions, micromeltings locations, craters from microexplosions, and tracks of the unusual shape presumably could be the transmutations of elements under low-energy actions in deuterium glow discharge plasma (2, 4-11). These anomalous elements were found in concentrations up to several percent, and they were not detected before the experiment.

The opportunity for nuclear changes initialized by low-energy reactions was shown for uranium in an earlier paper [12]. It was shown that the uranium after irradiation by deuterium ions 
in a glow discharge plasma with a current of $\sim 5$ milliamperes increased alpha, beta and gamma activity on both sides of the sample. This emission was shown to occur in subsequent analyses performed within a year of the experiment, and the change of amount of uranium and thorium in the cathode sample was also shown.

\section{CONCLUSIONS}

1. The following elements were found in Ti foil after deuterium glow discharge producing excess heat effect: $\mathrm{O}, \mathrm{F}, \mathrm{S}, \mathrm{Al}, \mathrm{Na}, \mathrm{Mg}, \mathrm{Fe}$, and Ni, typically in amounts of 0.3 to $0.5 \%$ but sometimes up to $10 \%$

2. The appearance of new elements within structural defects on the surface (in the micro explosion locations, micro craters, local melting zones, phases inclusions on the tracks and others formations) could be the result of non-equilibrium processes such as a micro arc with an overvoltage with some accelerated effect leading to fusion and fission reactions in the excited crystal lattice of cathode surface.

3. The appearance of most elements obeys the law of energy conservation.

4. Excess heat effect in Ti foil could be explained as a result of elements transmutation in the cathode under excitation of crystal lattice in the deuterium low energy glow discharge.

5. The similarity of resulting effects in the various processes (glow discharge, electrolysis with plasma discharge and other methods of excitation) could be due to the nature of the phenomena.

6. It is necessary to have more statistical results with sequential analysis for explanation and understanding of mechanism.

\section{REFERENCES}

1. Karabut A.B., Kucherov Ya.R., Savvatimova I.B. "Nuclear reaction on the cathode of glow discharge". Pisma v zhurnal technicheskoi fisiki (Letters in the technical physic journal) v.16, No.12, p. 53 (1990)

2. Karabut A.B., Kucherov Ya.R., Savvatimova I.B. "Nuclear product ratio for glow discharge in deuterium". Physics Letters A, 170, 265-272 (1992).

3. A.B. Karabut, Ya.R. Kucherov, I.B. Savvatimova The Investigation Of Deuterium Nuclei Fusion At Glow Discharge Cathode " Fusion Technology Vol.20 Dec.1991 (P.924-928)

4. Savvatimova I.B., Karabut A.B., Kucherov Ya.R. // Proc.of first Russian conference on cold fusion. Novorossiysk, 1993. Moscow, VENT, 1994, p.131.

5. Savvatimova I.B., Karabut A.B., Kucherov Ya. // Proc of the Fourth Int. Conf. on Cold Fusion, December, 1993, Hawaii, USA: EPRI. V1. N 3.7.

6. Savvatimova I.B., Kucherov Ya., Karabut A.B., "Cathode Material Change after Deuterium Glow Discharge Experiments, "Transaction of Fusion Technology “(December 1994); v.26, number 4T (1994), pp. 389-394.

7. Savvatimova I.B, Karabut A.B. Nuclear Reaction Products Registration on the Cathode after Deuterium Glow Discharge. Surface, V. 1, Moscow: RAN, 1996, p.63-75.

8. Savvatimova I.B., Karabut A.B. The chemical and isotope structure of Pd changes after ion irradiation in glow discharge. // Proc. of third Russian conference on cold fusion and nuclear transmutation, Sochy, October, 1995, M, 1996, p.20-49.

9. I.B Savvatimova, A.D.Senchukov, I.P. Chernov Transmutation Phenomena in the Palladium Cathode after Ions Irradiation at the Glow Discharge. Proceeding. The 6th Int. Conf. on Cold Fusion. Proc. Oct. 13-18, 1996- Japan, 1996, p.575-579.

10. I.Savvatimova Transmutation in cathode materials exposed at glow discharge by low energy ions. Nuclear phenomena or ion irradiation result? Proceeding. ICCF-7, 1998, 342-350.

11. I.B Savvatimova Reproducibility of experimental in glow discharge and process accompanying deuterium ions bombardment. ICCF8, Italian Physical Society, Bologna, Italy, 2000, P.277

12. J. Dash, I. Savvatimova, S. Frantz, E. Weis and H. Kozima, "Effects of Glow Discharge with Hydrogen Isotope Plasmas on Radioactivity” Proc.ICCF9 (2002), Proc. ICENES 2002, p. 122 (2002) .

13. V.A. Ivanov Excitation and effect of microplasma discharges on metals and alloys in a microwave plasma torch 2001, Applied physics, №2 p.5-39 
14. S. Szpak, P.A. Mosier-Boss and F.E. Gordon Precursors and the Fusion Reactions in Polarized Pd/D$\mathrm{D}_{2} \mathrm{O}$ System: Effect of an External Electric Field ICCF11, 2004.

15. Urutzkoev L.U., Filippov D.V. Influence of atomic electrons on the nuclear stability and the processes of the radioactive decay. Proc. of 10th Russian conference on the cold transmutation of the nuclear of chemical elements. Moscow, 2004.

16. Rodionov B.U. Nuclear transmutation in polyatomic quantum ensemble. Proc. of 10th Russian conference on the cold transmutation of the nuclear of chemical elements. M.2004

17. Yasuhiro Iwamura, Takehiko Itoh, Jirohta Kasagi et. al. Nuclear transmutation induced by deuterium permeation through the Pd complexes detected by surface and bulk analysis methods ICCF-11, Marseilles, France, 2004 